\title{
A comparative analysis of selected models of pedestrian-generated dynamic loads on footbridges - vertical loads
}

\author{
Kinga Marecik ${ }^{1, *}$ and Marek Pańtak ${ }^{1}$ \\ ${ }^{1}$ Cracow University of Technology, Institute of Building Materials and Engineering Structures, \\ Warszawska 24, Cracow 31-155, Poland
}

\begin{abstract}
In the paper the characteristics of selected dynamic load models of vertical forces generated during pedestrian movement (Vertical Ground Reaction Forces - $V G R F \mathrm{~s}$ ) and the results of dynamic numerical analyses and dynamic field tests of an exemplary footbridge were presented. Numerical analyses of the footbridge were performed taking into account recommendations of different authors and standards relating to $V G R F \mathrm{~s}$ models as well as $V G R F$ s measured by authors during laboratory tests using force platform. For comparative purposes, the dynamic field tests of the footbridge were carried out. The results and conclusions from comparative analyses of the dynamic responses of the footbridge obtained for various load models and field tests were presented.
\end{abstract}

\section{Introduction}

The ways of shaping footbridges have changed over the centuries. Along with the evolution of construction materials not only the size of the cross-sections and structural schemas but also the forms of structures of constructed bridges were changing. Nowadays architects are proposing more and more diverse, complex and abstract shapes of footbridges what have also an impact on its dynamics behavior. Footbridges currently erected, due to their lightness, increased spans length, smaller cross-sections of structural elements and often a complicated form, have become susceptible to dynamic loads generated by pedestrians. The problem of excessive vibration of the footbridges has been clearly noticed at the end of twentieth century (e.g. Millennium Footbridge in London, Léopold Sédar Senghor Footbridge in Paris) and became the subject of interest of a large group of engineers and scientists all over the world. This led to introduction of requirements on the dynamic analyses of footbridges and recommendations related to the assessment of the comfort of use of footbridges due to its vibrations in design standards or design guidelines in different countries. Nonetheless, the problem of footbridge vibration was also noticed earlier and noted in older papers and design standards $[1,2]$.

Dynamic problems of footbridge can occur when the natural frequency of the structure coincides with the frequency of pedestrian movement. The values of stepping frequencies

\footnotetext{
* Corresponding author: marecik.kinga@gmail.com
} 
for various form of activity are in the following ranges [3]: $1.4-2.4 \mathrm{~Hz}$ - walking, $1.9-$ $3.3 \mathrm{~Hz}$ - running, $1.3-3.4 \mathrm{~Hz}$ - jumping.

In general, the fundamental frequency of footbridge depends on several coefficients, i.e. structural elements cross-section, materials, static scheme and span length of construction that all have an impact on the mass and the stiffness of structure which are strictly correlated with the formula of the objects natural frequency. According to the research that were carried out on existing footbridges [4] it can be seen that for span length in range $20-30 \mathrm{~m}$ natural vibration frequencies of the structures are $2.0 \mathrm{~Hz}$ to $4.0 \mathrm{~Hz}$; for span length $30-50 \mathrm{~m}$ natural vibration frequencies are $1.5 \mathrm{~Hz}$ to $4.0 \mathrm{~Hz}$; and for span length $50-100 \mathrm{~m}$ natural vibration frequencies are less or equal to $3 \mathrm{~Hz}$. For the given ranges of spans approximately $60 \%, 84 \%$ and $40 \%$ of the structures respectively has a fundamental natural vibration frequency in the frequency range of human movement. These footbridges are exposed to excitation of resonant vibrations. This affects the need to perform the dynamic analyses of the footbridges using appropriate models of pedestriangenerated dynamic loads.

\section{Models of pedestrian-generated vertical dynamic loads}

Pedestrian-generated vertical dynamic loads (Vertical Ground Reaction Forces (VGRFs)) are described by various authors in form of different mathematical models. To study the accuracy and correctness of some of these load models the three load models representing the $V G R F$ s generated during human walking (Eqs. (1) - (3)) and the VGRF measured by means of force platform during laboratory tests of walking person were analyzed.

The load model No. 1 was adopted in accordance with BS-5400-2:1978 [1] as a pedestrian load model described by means of a formula:

$$
F(t)=180 \sin \left(2 \pi \cdot f_{0} \cdot t\right)
$$

where: $f_{0}$ - natural vibration frequency $[\mathrm{Hz}], t-$ time steep [s].

The model No. 2 was taken from NA-BS-EN 1991-2:2003 [5]. The function representing $V G R F \mathrm{~s}$ is much more complex than given by the equation (1) and depends on several coefficients depending on the type of pedestrian traffic, footbridge location, footbridge natural vibration frequency and its mode shape, value of the logarithmic damping ration and is given as follows:

$$
F(t)=F_{0} \cdot k\left(f_{0}\right) \sqrt{1+\gamma(N-1)} \cdot \sin \left(2 \pi \cdot f_{0} \cdot t\right)
$$

where: $F_{0}$ - reference amplitude $[\mathrm{N}], k\left(f_{0}\right)$ - combined factor, $\gamma$ - reduction factor for unsynchronized action of pedestrians, $N$ - the number of pedestrian in the group, $f_{0}$ natural vibration frequency $[\mathrm{Hz}], t-$ time steep $[\mathrm{s}]$.

The load model No. 3 was the $V G R F$ pattern generated by one foot [6]. It represents more adequate values of force generated during pedestrian movement by each foot and shows approximation of the accurate physical situation of generated vertical force during walking. It is described by the formula:

$$
F(t)=G \sum_{i=1}^{5} A_{i} \sin \left(\frac{\pi \cdot i \cdot t}{t_{c}}\right)
$$

where: $G$ - body weight of walking person $[\mathrm{N}], t_{c}$ - time of the foot contact with the ground [s] ( $t_{c} \approx 1.32 T_{w}, T_{w}$ - period of walk, $\left.T_{w}=1 / f_{0}\right), f_{0}$ - natural vibration frequency, $t$ - time steep [s], $A_{i}$ - amplitude of the $i$-th harmonics, $i$ - the number of the harmonics, $i=1-5$. 
The last load model (Lab Test $V G R F$ ) used in analyses come from laboratory tests and represents the real values of dynamic impact of human on the ground. The Lab Test VGRF was obtained during gait tests of one person (body weight $G=840 \mathrm{~N}$ ) carried out using the force platform Zebris FDM-1.5.

All $V G R F$ s functions representing by loads models No. $1-3$ and Lab Test VGRF are presented in Fig. 1. In all cases, walking frequency was assumed as equal to $2.38 \mathrm{~Hz}$. The formulas components in equations (2) and (3) were chosen based on the parameters of selected steel footbridge in Osjaków briefly characterized in Chapter 3.

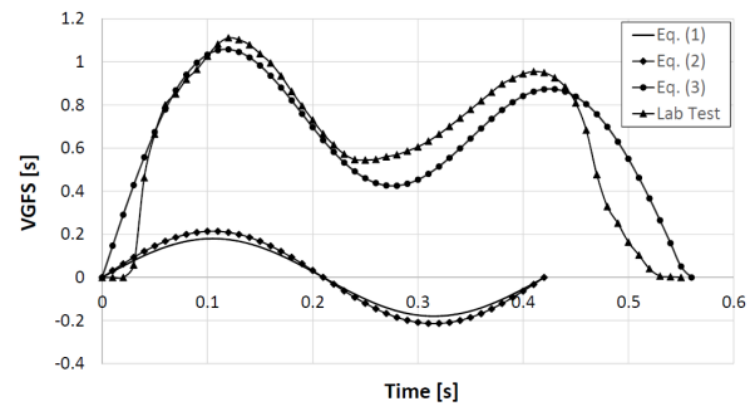

In equations (2) and (3) the following values were assumed:

$\begin{array}{ll}F_{0}=280 \mathrm{~N} & G=840 \mathrm{~N} \\ k\left(f_{0}\right)=0.72 & A_{1}=1.047 \\ \gamma=0.13 & A_{2}=0.092 \\ N=2 & A_{3}=0.544 \\ \text { Class A } & A_{4}=0.0533 \\ & A_{5}=0.00176\end{array}$

Fig. 1. The comparison of the values of the $V G R F \mathrm{~s}$ load models used during footbridge analysis.

\section{Dynamic analysis of the footbridge}

To perform comparative analyses of all load models characterized in Chapter 2, a numerical 3D model of a selected steel footbridge characterized by high dynamic susceptibility was made.

\subsection{Characteristic of the footbridge}

Footbridge in Osjaków is a steel footbridge with a span length $L=50.00 \mathrm{~m}$. The general view and the cross-section of the footbridge are shown in Fig 2.
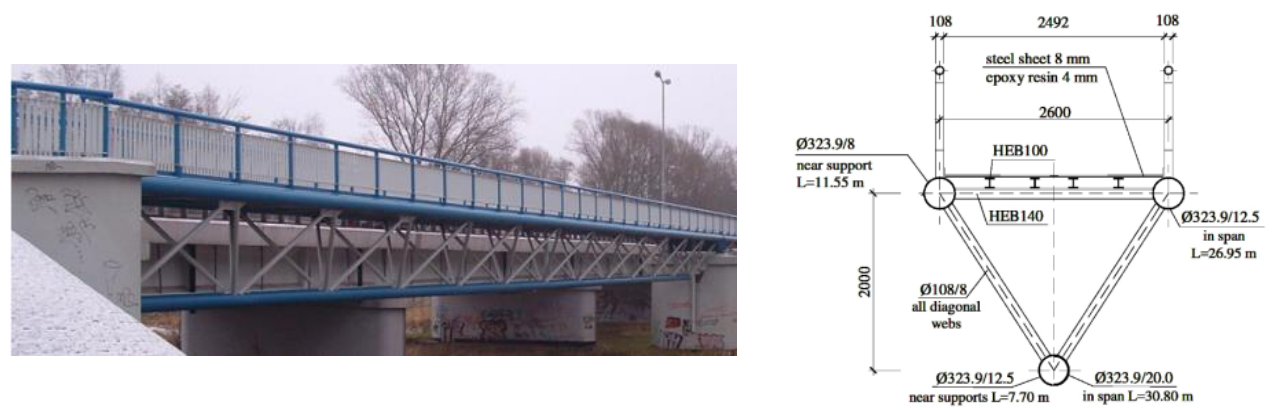

Fig. 2. General view and cross-section of footbridge in Osjaków.

A main girder of the footbridge is designed as a spatial truss contains 13 pyramidal parts which are spaced in intervals of $3.85 \mathrm{~m}$. Upper and lower chord of the truss consists of tubular section $\varnothing 323.9 \mathrm{~mm}$ and have variable thicknesses along with the length of the span length. The upper and the lower chord are connected by a three-dimensional system of diagonals, posts and vertical beams. The deck of the footbridge $(8.0 \mathrm{~mm}$ steel sheet $)$ rests on the longitudinal beams HEB100 supported on cross-beams HEB140. 


\subsection{Dynamic characteristic of the footbridge}

The dynamic characteristic of the footbridge was obtained from the numerical analysis and verified during the dynamic field tests of the footbridge. A fundamental natural vibration frequency of the footbridge is $f_{0}=2.38 \mathrm{~Hz}$ (vertical mode shape, Fig. 3). This value is in the stepping frequency range presented in Chapter 1 corresponding to fast walking or slow running (jogging). Further dynamic analyses of the footbridge were made taking into account the $V G R F s$ generated during walking.

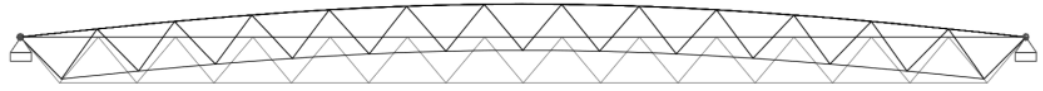

Fig. 3. The fundamental mode shape of the footbridge in Osjaków $f_{0}=2.38 \mathrm{~Hz}$.

In analyses the vibration dumping parameter - the logarithmic decrement $\delta=0.0076$ (corresponding damping ratio $\zeta=0.0012$ ) determined on the basis of the footbridge field tests results obtained during resonant vibration excitation by one walking person was used.

\subsection{Comparison of acceleration obtained for different load models}

Numerical dynamic analyses of the footbridge were made using the dynamic load models No. 1- 3 and the Lab Test $V G R F$ described in Chapter 2. As a results the values of vibration accelerations of structure ware obtained. The maximum values of acceleration received from dynamic analyses are shown in Tab. 1. As a comparative value the value of maximum acceleration obtained during the in-situ dynamic tests of the structure in the case of resonant excitation of vibrations by one walking person was used (last row in Tab. 1).

Table 1. Vibration acceleration obtained during numerical analysis and in situ tests.

\begin{tabular}{|c|c|c|}
\hline Load model & Mass [N] & Vibration acceleration $\left[\mathbf{m} / \mathbf{s}^{\mathbf{2}}\right]$ \\
\hline Eq. (1) & - & 0.76 \\
\hline Eq. (2) & - & 1.15 \\
\hline Eq. (3) & $840 \mathrm{~N}$ & 2.28 \\
\hline Lab Test $V G R F$ & $840 \mathrm{~N}$ & 2.09 \\
\hline In-Situ Test & $840 \mathrm{~N}$ & 1.95 \\
\hline
\end{tabular}

In Fig. 4 the dynamic response of the footbridge as a function of time obtained for models No. 1 and 2, Lab Test $V G R F$ and In-Situ Test were presented.

a)

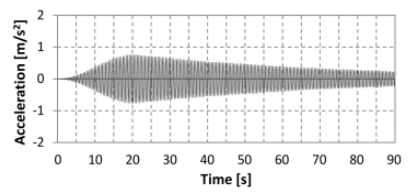

c)

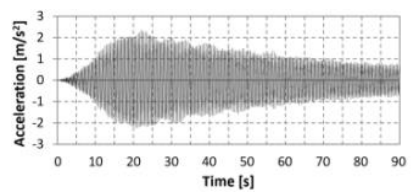

b)

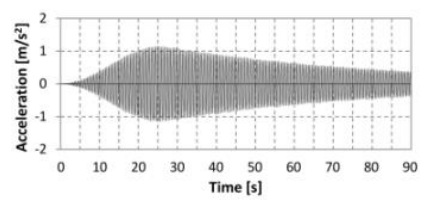

d)

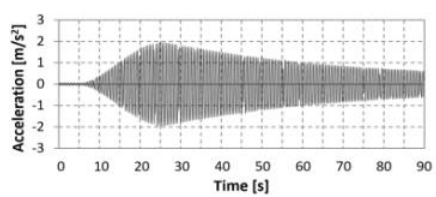

Fig. 4. The dynamic response of the footbridge obtained for a) model No. 1, b) model No. 2, c) Lab Test $V G R F$, d) In-Situ Test. 


\section{Conclusions}

The analysis of the results allows to formulate some important conclusions:

1. The force amplitudes in model No. 1 and 2 are $F_{0,(I)}=180 \mathrm{~N}$ and $F_{0,(2)}=214 \mathrm{~N}$ respectively. These values differ insignificantly. For number of pedestrian $N=1$ and $k\left(f_{0}\right)=0.643$ force amplitude $F_{0,(2)}=180 \mathrm{~N}$. This indicates a similar method of calibration of the models No. 1 and 2 for the case of walking of one person.

2. The values of vibration accelerations determined using models No. 1 and 2 are underestimated. Models No. 1 and 2 are inappropriate to determine the dynamic response of the footbridges induced by one person walking in resonance with natural vibration frequency of the structure. The vibration amplitudes calculated using models No. 1 and 2 are respectively 2.57 and 1.69 times smaller than In-Situ Tests result. It can mean that the models No. 1 and 2 are calibrated to determine the dynamic response of the structure induced by walking person unsynchronized with the natural vibration frequency of the structure. To confirm this observation, further analyses and dynamic in-situ tests are necessary. Uncritical use of models No. 1 and 2 can lead to incorrect estimation of vibration amplitudes.

3. The convergence of vibration acceleration value estimated using model No. 2 with In-Situ Test results is reached after increasing the amplitude $F_{0,(2)}$ of about $62 \%$ to the value of $346 \mathrm{~N}\left(F_{0,(2)}^{\prime}=1.62 F_{0,(2)}\right)$. This correspond to the assumption, according to [5], pedestrian number $N=16$ in model (2). To achieve the convergence of results for the model No 1, the amplitude $F_{0,(l)}$ should be multiplied by the factor 2.50 and increased to the value of $450 \mathrm{~N}\left(F_{0,(I)}^{\prime}=2.5 F_{0,(I)}\right)$. The differences in new force amplitudes in models No. 1 and 2 resulting from differences in the walking speed defined for the models $\left(0.9 f_{0}=2.14 \mathrm{~m} / \mathrm{s}\right.$ and $1.7 \mathrm{~m} / \mathrm{s}$ respectively), which affect the number of the $V G R F$ s included in 3D computational model of the footbridge.

4. The Lab Test $V G R F$ was a force model that gave the value of vibration acceleration closest to In-Situ Test result (with only 7\% of discrepancy). This result can be assumed as a very accurate estimation of vibration amplitudes of the footbridge.

5. The values of vibration accelerations determined using model No. 3 exceed the In-Situ Tests result by $17 \%$. This result can be considered as a good and conservative estimation of vibration amplitude. Moreover, using the models No. 3 the $V G R F$ s patterns (Fig. 1) and the values of vibration accelerations (Tab. 1) are similar to those obtained using the Lab Test $V G R F$. This proves correctness of the $V G R F$ s pattern determination using equation (3). Model No. 3 can be considered correct and can be used in the design process since it gives good and conservative estimation of the vibration amplitudes during resonance excitation.

\section{References}

1. J. Blanchard, B.L. Davies, J.W. Smith, Proc. DOE and DOT TRRL Symp. on Dynamic Behaviour of Bridges, (1977)

2. BS-5400-2:1978, Steel, concrete and composite bridges. Part 2: Specification for loads, (BSI, 1978)

3. H. Bachmann, W. Ammann, F. Deischl et al. Vibration Problems in Structures: Practical Guidelines, (Birkäuser Verlag, Basel, Boston, Berlin, 1995)

4. O. Fisher, M. Pirner, Proc. $2^{\text {nd }}$ European-African Conf. on Wind Engineering (1997)

5. NA-BS-EN 1991-2:2003, UK National Annex to Eurocode 1: Actions on structures Part 2: Traffic loads on bridge, (BSI, 2008)

6. Q. Li, J. Fan et al., J. Sound Vibr. 329, 13 (2010) 